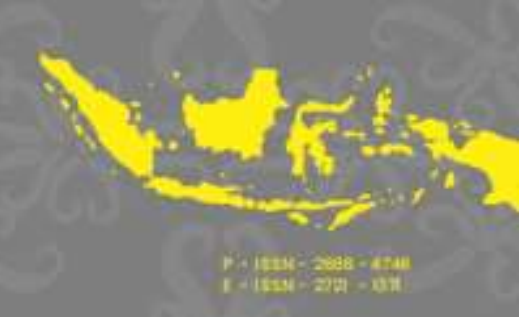

\title{
Peran Mediasi Work Engagement Pada Leader Member Exhange terhadap Job Performance pada Karyawan Resort "XYZ" Malang
}

\author{
Vincent Yongky ${ }^{1}$, Tri Siwi Agustina ${ }^{2}$ \\ 1,2Department of Mangement, Airlangga University, Surabaya, 60286, Indonesia \\ vvincentyongky@yaoo.com; ${ }^{2}$ siwi@feb.unair.ac.id
}

\begin{abstract}
ABSTRAK
Penelitian ini menggunakan obyek salah satu resort di kota Malang yang mengalami pertumbuhan bisnis cukup pesat di dalam lingkungan destinasi wisata Malang. Fokus penelitian ini adalah kinerja karyawan. Penelitian ini bertujuan untuk mengkaji mekanisme leader member exchanget terhadap job performance dengan menggunakan work engagement sebagai mediasi. Studi kuantitatif ini didasarkan pada data yang dikumpulkan menggunakan kuesioner yang diberikan kepada 100 responden karyawan tetap resort "XYZ" di Malang dan menggunakan teknik partial least square (PLS) untuk analisis data. Hasil analisis data menggunakan PLS menemukan bahwa work engagement memediasi hubungan antara leader member exchange dan job performance. Pengembangan kualitas hubungan leader dan karyawan amat dibutuhkan untuk meningkatkan kinerja karyawan di sebuat tempat
\end{abstract}

ARTICLE HISTORY

Submitted:21.06.2021

Revised:22.06.2021

Accepted:08.07.2021

Online first:10.07.2021

\section{KEYWORDS}

Work engagement, Leader-member exchange, Job performance. 


\section{Pendahuluan}

Perkembangan bisnis global memaksa dunia bisnis khususnya di bidang jasa untuk mampu memberikan pelayanan baik dan cepat pada pelanggan. Dikatakan oleh Schneider dan Bowen (2010), organisasi harus mampu melampaui ekspektasi pelanggan dalam memenuhi permintaannya jika ingin memenangkan persaingan tersebut.

Menurut Dirjen Pariwisata, hotel adalah suatu jenis akomodasi yang mempergunakan sebagian atau seluruh bangunan, untuk menyediakan jasa penginapan, makan dan minum, serta jasa lainnya bagi umum, yang dikelola secara komersial. Sebagai organisasi di bidang jasa, hotel perlu memberikan layanan terbaiknya kepada para pelanggan. Parker (2007) mengatakan bahwa kinerja karyawan adalah faktor kritikal dari individu, team, dan menentukan efektivitas organisasi.

Sehubungan dengan itu diharapkan dengan adanya job performance yang baik, mampu memberikan pelayanan yang terbaik bagi para pelanggan. Kinerja individu diharapkan dapat sesuai dengan target dan tujuan organisasi.

Kehidupan yang dinamis antar individu dalam perusahaan membuat adanya hubungan yang dipengaruhi oleh leader member exchange. Leader member exchange digambarkan sebagai kualitas hubungan kerja antara seorang karyawan dengan pimpinannya (Dansereau et al., 1975). Leader member exhange memiliki indikator tingginya tingkat saling percaya, rasa hormat, kesetiaan, dan saling melakukan kewajiban (Olutade, 2015). Kualitas leader member exchange berhubungan dengan job performance karyawan karena karyawan memiliki akses yang lebih ketika memiliki hubungan yang baik dengan pimpinannya.

Hubungan antara pimpinan dan karyawan ini juga menentukan work engagement dari setiap karyawan yang ada. Work engagement merupakan sebuah kondisi kerja yang positif yang dicirikan dengan vigor, dedication, dan absorption (Schaufeli et al., 2006). Meskipun work engagement karyawan merupakan sesuatu yang penting bagi perusahaan, namun database internasional yang meliputi berbagai industri, menyatakan hanya $20 \%$ karyawan yang memiliki work engagement yang tinggi terhadap pekerjaannya. Pemimpin yang memiliki hubungan leader member exchange yang baik merupakan bentuk representasi 
dari sumber daya yang mampu memenuhi target pekerjaan, pengembangan personal, dan meningkatkan work engagement (Upasna, 2012).

Resort "XYZ" di Kota Malang merupakan hotel bintang 5 yang merupakan anggota dari jaringan grup hotel internasional yang berpusat di Prancis. Resort "XYZ" di Kota Malang merupakan hotel berskala internasional pertama di Kota Malang. Hal ini menjadi peluang tersendiri karena Kota Malang merupakan destinasi wisata yang sedang berkembang di Jawa Timur. Dengan 200 orang lebih karyawan, Resort “XYZ" di Kota Malang terus berusaha agar dengan sumber daya manusia yang ada dapat memenuhi apa yang menjadi keinginan pelanggan.

Dalam bisnis perhotelan, pelayanan pelanggan merupakan ujung tombaknya. Hal ini dimulai dari job performance setiap lini karyawan yang ada dalam memenuhi setiap permintaan pelanggan. Data yang ditarik dari OTA (Online Travel Agent), yang menjadi wadah bagi tamu untuk melakukan reservasi hotel, menunjukkan poin yang tinggi bagi resort "XYZ" dalam memberikan pelayanan pada pelanggan. Penilaian tersebut meliputi berbagai faktor antara lain kebersihan, keamanan, layanan, makanan, fasilitas, lokasi, dan kenyamanan.

Untuk meningkatkan kinerja karyawan perlu adanya dukungan atau dorongan dari organisasi yang senantiasa menghargai kontribusi karyawan, menyediakan kondisi kerja yang baik, dan memberikan kesejahteraan bagi mereka (Rhoades \& Eisenberger, 2002). Selain dukungan organisasi, perusahaan senantiasa mengharapkan karyawannya untuk memiliki kinerja tinggi dan diharapkan dapat membuat perusahaan bersaing dengan perusahaan lain, tentunya kinerja itu juga harus diikuti dengan work engagement yang harus dimiliki oleh karyawan,karena karyawan merupakan komponen utama suatu perusahaan dan menjadi pelaku dalam setiap aktivitas perusahaan. Menurut Dessler (2010) sumber daya yang dimiliki perusahaan seperti modal, metode, dan mesin tidak bisa memberikan hasil yang maksimum bagi perusahaanapabila tidak didukung oleh sumber daya manusia yang mempuyai totalitas kerja kepada perusahaan. Sesuai dengan fenomena dan penjelasan di atas, maka penelitian bertujuan melakukan pengujian Peran Mediasi 
Work Engagement Pada Leader Member Exhange terhadap Job Performance pada Karyawan Resort "XYZ” Malang.

\section{Review Tinjauan Pustaka}

\subsection{Leader Member Exhange}

Di dalam sebuah organisasi, peran sebuah hubungan timbal balik antara pimpinan dan bawahan atau karyawan sangatlah penting. Hubungan tersebut dikenal dengan konsep Leader-Member Exchange atau disebut LMX. LMX merujuk kepada pentingnya sebuah peran pemimpin dalam membentuk attitude dan performance karyawan (Kim dan Koo, 2017). Teori LMX menyatakan bahwa bawahan cenderung mengembangkan hubungan timbal balik yang unik terhadap atasannya dan hal ini berpengaruh positif terhadap outcome pegawai dalam pekerjaannya (Breevaart, 2015). Leader-Member Exchange merupakan bentuk peningkatan kualitas hubungan antara pemimpin dengan karyawan yang mampu meningkatkan kinerja keduanya (Morrow et al., 2005).

Sebagai bentuk timbal balik atas keteladanan yang diberikan atasan terhadap work performance (misalnya secara konsisten mau bekerja lembur untuk mencapai deadline), pengikut (follower) mendapatkan hak khusus (misalnya akses untuk mendapat informasi), peluang untuk meningkatkan karir (misalnya pekerjaan khusus), serta meningkatnya tingkat keleluasaan dalam menyelesaikan pekerjaan. Hal ini akan membuat setiap orang yang di dalamnya dengan mudah akan mendapatkan dukungan dari pimpinan, munculnya job-related information, greater job latitude, dan meningkatnya tingkat kinerja atau job performance (Thomas dan Lankau, 2009).

Hingga pada tahun 1998, Liden dan Maslyn memperkenalkan Multidimensional Measure of Leader Member Exchange atau LMX-MDM. LMX-MDM menjelaskan bahwa terdapat 4 hal yang menjadi tolak ukur untuk melihat kualitas sebuah hubungan leadermember exchange, yaitu Affect,Loyalty, Contribution, dan Professional Respect (Joseph et al., 2015).

Berdasarkan teori di atas, dapat dilihat bahwa teori LMX adalah untuk menjelaskan hubungan timbal balik pimpinan terhadap karyawan, anggota, tim, atau organisasi yang 
akan mempengaruhi sebuah hubungan masing-masing menjadi hubungan yang baik atau sebaliknya, yang nantinya dapat berdampak langsung kepada individu, kelompok dan organisasi tersebut

\subsection{Work Engagement}

Work engagement merupakan konsep yang relatif baru dari psikologi organisasi dan telah memiliki definisi teoritis serta instrument pengukuran (Hallberg, 2006). Level engagement yang tinggi membawa kepada hasil yang positif terhadap kualitas dari pekerjaan dan pengalaman dalam melakukan pekerjaan individu serta meningkatnya level organisasi yang dapat dilihat dari pertumbuhan dan produktivitas organisasi tersebut (Min, 2017). Berdasarkan definisi-definisi tersebut, work engagement dapat disimpulkan sebagai cara pandang seseorang untuk termotivasi dan berhubungan dengan keadaan pemenuhan karyawan yang ditandai dengan energi dan resiliensi mental yang tinggi selama bekerja, rasa antusiasme, merasa penting serta bangga terhadap pekerjaan, dan fokus menikmati pekerjaan.

\subsection{Job Performance}

Job Performance merupakan hasil atau keluaran dari suatu proses. Menurut pendekatan perilaku dalam manajemen, kinerja adalah kuantitas atau kualitas sesuatu yang dihasilkan atau jasa yang diberikan oleh seseorang yang melakukan pekerjaan (Luthans, 2005). Robbins (2001) mendefinisikan job performance sebagai ukuran hasil kerja yang mana ukuran tersebut menggambarkan sejauh mana individu tersebut melakukan tugasnya dalam rangka mencapai ketentuan yang sudah ditetapkan. Mathis dan Jackson (2006) mengungkapkan penilaian job performance karyawan adalah proses mengevaluasi seberapa baik karyawan menjalankan pekerjaan mereka jika dibandingkan dengan seperangkat standar, dan kemudian mengkomunikasikan informasi tersebut kepada karyawan

\section{Metodologi Penelitian}

Penelitian ini dilakukan pada resort "XYZ" di Malang, Jawa Timur, sedangkan fokus 
penelitian ini adalah kinerja karyawan pada resort "XYZ". Pendekatan yang digunakan dalam penelitian ini adalah pendekatan kuantitatif. Teknik pengumpulan data menggunakan kuesioner dengan skala Likert 1-5. Populasi dalam penelitian ini adalah 137 karyawan tetap. Peneliti menggunakan proportional sampling dengan menetapkan 100 responden yang dijadikan sampel berdasarkan kriteria bahwa sampel adalah karyawan yang mewakili tiap departemen yang ada. Responden juga memberikan tanggapan terkait pertanyaan tentang karakteristik demografi meliputi usia, jenis kelamin, pendidikan terakhir, dan lama bekerja.

Teknik analisis data dalam penelitian ini menggunakan path analysis yang merupakan metode analisis yang didasarkan pada perhitungan kuatnya hubungan kausal antara korelasi dari beberapa variabel.Penelitian ini menggunakan pendekatan Structural Equation Modeling (SEM) dengan menggunakan path diagram yang dimungkinkan untuk menganalisa semua observed variabel sesuai dengan teori yang dibangun dan analisa SEM yang digunakan adalah Partial Least Square (PLS)

\section{Hasil dan Diskusi}

Pembahasan tentang hasil dan diskusi, diawali dengan penjelasan tentang karakteristik responden pada penelitian ini seperti nampak pada :

Tabel Karakteristik Gender \& Usia Responden

\begin{tabular}{|c|c|c|c|c|}
\hline Usia & Pria & Wanita & Jumlah & \% \\
\hline $\mathbf{2 1}$ & 18 & 14 & 32 & $32 \%$ \\
\hline $\mathbf{2 2 - 2 7}$ & 25 & 8 & 33 & $33 \%$ \\
\hline $\mathbf{2 8 - 3 3}$ & 13 & 1 & 14 & $14 \%$ \\
\hline $\mathbf{3 4 - 3 9}$ & 12 & 2 & 14 & $14 \%$ \\
\hline $\mathbf{4 0}$ & 7 & 0 & 7 & $7 \%$ \\
\hline Total & 75 & 25 & 100 & $100 \%$ \\
\hline
\end{tabular}

Sumber : data diolah peneliti (2021) 
Tabel Karakteristik Pendidikan Responden

\begin{tabular}{|c|c|c|}
\hline Pendidikan & Jumlah & Presentase \\
\hline SMA & 67 & $67 \%$ \\
\hline Diploma & 14 & $14 \%$ \\
\hline Sarjana & 19 & $19 \%$ \\
\hline Total & 100 & $100 \%$ \\
\hline
\end{tabular}

Sumber : data diolah peneliti (2021)

Tabel Karakteristik Masa Kerja Responden

\begin{tabular}{|c|c|c|}
\hline Masa Kerja & Jumlah & Persentase \\
\hline$\leq 1$ tahun & 52 & $52 \%$ \\
\hline $2-5$ tahun & 48 & $48 \%$ \\
\hline$\geq 5$ tahun & 0 & $0 \%$ \\
\hline Total & 100 & $100 \%$ \\
\hline
\end{tabular}

Sumber : data diolah peneliti (2021)

Koefisien determinasi berfungsi untuk mengukur seberapa jauh kemampuan model dalam menerangkan variasi variabel dependen yang tersebar antara 0 hingga 1 (Ghozali, 2008). Besarnya koefisien determinasi dapat dilihat pada tabel $R$-square. Besarnya nilai koefisien determinasi dapat dihitung dengan cara mengalikan nilai $R$-square dengan 100\%. Jika hasil menunjukkan angka di atas 67\% maka dapat diindikasikan koefisien determinasi tersebut tergolong baik. Apabila hasil menunjukkan angka di antara 33\% hingga 67\% maka dapat dikategorikan sebagai koefisien determinasi moderat. Sedangkan jika angka koefisien determinasi ada di antara 19\% hingga 33\% maka mengindikasikan nilai yang lemah (Ghozali, 2006). Berikut adalah hasil pengujian yang menunjukkan nilai koefisien determinasi:

Nilai R-Square

\begin{tabular}{|l|c|c|}
\hline \multicolumn{1}{|c|}{ Var } & R-Square & R-Square Adjusted \\
\hline Work Engagement & 0,412 & 0,405 \\
\hline Job Performance Karyawan & 0,508 & 0,497 \\
\hline
\end{tabular}


Dari Tabel diatas dapat dilihat bahwa variabel work engagement memiliki nilai Rsquare sebesar 0,412 dan untuk variabel job performance sebesar 0,508. Nilai R-square work engagement sebesar 0,412 dapat dijelaskan bahwa work engagement dapat digambarkan oleh absorption, dedication, dan vigor sebesar $41,2 \%$. Nilai $R$-square job performance sebesar 0,508 dapat dijelaskan bahwa job performance dapat digambarkan oleh task adaptivity, task proactivity, dan task proficiency sebesar 50,8\%.

\subsection{Pengujian Hipotesis}

Hasil uji hipotesis dievaluasi berdasarkan nilai T-statistics. Estimasi koefisien jalur menunjkkan nilai estimasi yang menggambarkan hubungan antar variabel laten yang diperoleh dengan prosedur bootstrapping. Item pengukuran yang digunakan dikatakan signifikan apabila nilai T-statistics lebih besar dari 1,96 pada taraf signifikansi 5\% (Ghozali, 2008).

\section{Path Coefficients}

\begin{tabular}{|l|c|c|c|}
\hline & $\begin{array}{c}\text { Original } \\
\text { Sample }\end{array}$ & T-Statistics & Ket \\
\hline $\begin{array}{l}\text { Leader Member Exchange }> \\
\text { Job Performance Karyawan }\end{array}$ & 0,574 & 6,034 & Signifikan \\
\hline $\begin{array}{l}\text { Leader Member Exchange }> \\
\text { Work Engagement }\end{array}$ & 0,642 & 9,364 & Signifikan \\
\hline $\begin{array}{l}\text { Work Engagment }> \\
\text { Job Performance Karyawan }\end{array}$ & 0,618 & 5,033 & Signifikan \\
\hline
\end{tabular}

Berdasarkan Tabel diatas, LMX memiliki pengaruh signifikan terhadap Job Performance Karyawan dikarenakan angka signifikansiya sebesar 6,034 dimana lebih besar dari nilai kritis 1,96 pada taraf signifikansi 5\%. Maka dari itu, hipotesis pertama yang menyatakan bahwa LMX memiliki pengaruh signifikan terhadap Job Performance Karyawan tidak dapat diterima dikarenakan memiliki nilai T-Statistic 6,034 $<1$,96.Berdasarkan Tabel 4.14, LMX memiliki pengaruh signifikan terhadap work engagement dengan signifikansi sebesar 9,364 yang lebih besar dari nilai kritis 1,96 pada taraf signifikansi 5\%. Maka dari itu, hipotesis kedua yang menyatakan bahwa LMX memiliki pengaruh signifikan terhadap 
Work Engagement dapat diterima dikarenakan memiliki nilai T-Statistic 9,364 > 1,96.

Berdasarkan Tabel 4.14, Work Engagement memiliki pengaruh signifikan terhadap Job Performance Karyawan dikarenakan angka signifikansiya sebesar 5,033 dimana lebih besar dari nilai kritis 1,96 pada taraf signifikansi 5\%. Maka dari itu, hipotesis ketiga yang menyatakan bahwa Work Engagement memiliki pengaruh signifikan terhadap Job Performance Karyawan dapat diterima dikarenakan memiliki nilai T-Statistic 5,033 >1,96.

\subsection{Pengaruh LMX terhadap Job Performance}

Hasil pengujian dengan menggunakan Partial Least Square (PLS) menunjukkan bahwa Leader Member Exchange berpengaruh signifikan terhadap Job Performance Karyawan (Nilai T-statistic sebesar 6,034 > 1,96) pada lingkungan kerja Resort “XYZ" di Kota Malang.

Tingginya pengaruh Leader Member Exchange terhadap Job Performance karyawan disebabkan oleh tingginya tingkat kepercayaan pimpinan kepada karyawan yang mampu menyelesaikan pekerjaan dengan baik. Hasil kerja karyawan ditunjukkan dengan tingginya angka kemampuan karyawan dalam penyelesaian tugasnya sesuai dengan ekspektasi pimpinan. Kesuksesan pimpinan dalam memimpin karyawan sendiri tidak lepas dari dukungan karyawannya. Karyawan merasa pimpinan mampu memberi semangat, kepercayaan, dan dukungan apabila terdapat karyawan yang merasa kesulitan dalam menyelesaikan pekerjaannya.

\subsection{Pengaruh LMX terhadap Work Engagement}

Hasil pengujian dengan menggunakan Partial Least Square (PLS) menunjukkan bahwa Leader Member Exchange berpengaruh signifikan terhadap Work Engagement (Tstatistic sebesar 9,364 > 1,96) pada lingkungan kerja Resort “XYZ" di Kota Malang.

Tingginya pengaruh Leader Member Exchange terhadap Work Engagement karyawan disebabkan oleh tingginya tingkat respect pimpinan kepada karyawan yang mampu membuat karyawan merasa nyaman dengan tempat kerjanya. Engagement karyawan ditunjukkan dengan tingginya rasa bangga karyawan terhadap pekerjaannya serta karyawan menjadi giat bekerja dengan adanya kualitas Leader Member Exchange yang 
tinggi. Adanya saling respect antara pimpinan dan karyawan sendiri tidak lepas dari dukungan antara pimpinan dan karyawan. Karyawan merasa pimpinan mampu menghargai dan memberikan semangat dalam penyelesaian pekerjaan.

\subsection{Pengaruh Work Engagement terhadap Job Performance}

Hasil pengujian dengan menggunakan Partial Least Square (PLS) menunjukkan bahwa Work Engagement berpengaruh signifikan terhadap Job Performance Karyawan (Nilai T-statistic sebesar 5,033 > 1,96) pada lingkungan kerja Resort "XYZ" di Kota Malang.

Tingginya pengaruh Work Engagement terhadap Job Performance karyawan disebabkan oleh adanya rasa terlibat dan kebanggaan di dalam pekerjaan sehingga menghasilkan performance yang tinggi di kalangan karyawan. Hasil kerja karyawan ditunjukkan dengan tingginya angka kemampuan karyawan dalam penyelesaian tugasnya sesuai dengan ekspektasi pimpinan. Performance karyawan yang tinggi merupakan pengaruh dari rasa terlibat dalam pekerjaan setiap karyawan yang tinggi. Karyawan merasa pekerjaannya mampu memberi rasa bangga, inspirasi, dan membuat giat dalam bekerja sehingga target-target dalam pekerjaan dapat dipenuhi dan menghasilkan Job Performance yang tinggi.

Table 1. Uji Construct Validity

\begin{tabular}{|l|c|c|}
\hline \multicolumn{1}{|c|}{ Variabel } & Skor AVE & Keterangan \\
\hline Leader Member Exchange & 0,527 & Valid \\
\hline Work Engagement & 0,733 & Valid \\
\hline Job Performance & 0,672 & Valid \\
\hline
\end{tabular}

Table 2. Uji Composite Reliability

\begin{tabular}{|l|c|c|c|}
\hline \multicolumn{1}{|c|}{ Var } & $\begin{array}{c}\text { Cronbach's } \\
\text { Alpha }\end{array}$ & $\begin{array}{c}\text { Composite } \\
\text { Reliability }\end{array}$ & Ket \\
\hline Leader Member Exchange & 0,774 & 0,829 & Reliabel \\
\hline $\begin{array}{l}\text { Work } \\
\text { Engagement }\end{array}$ & 0,868 & 0,892 & Reliabel \\
\hline Job Performance Karyawan & 0,842 & 0,877 & Reliabel \\
\hline
\end{tabular}




\section{Table 3. Nilai R-Square}

\begin{tabular}{|l|c|c|}
\hline \multicolumn{1}{|c|}{ Var } & R-Square & R-Square Adjusted \\
\hline Work Engagement & 0,412 & 0,405 \\
\hline Job Performance Karyawan & 0,508 & 0,497 \\
\hline
\end{tabular}

\section{Kesimpulan}

Berdasarkan analisis dan pengujian hipotesis yang telah dilakukan, diperoleh kesimpulan sebagai berikut:

1. Terdapat pengaruh yang signifikan antara Leader Member Exchange terhadap Job Performance karyawan.

2. Terdapat pengaruh yang signifikan antara Leader Member Exchange terhadap Work Engagement karyawan.

3. Terdapat pengaruh yang signifikan antara Work Engagement terhadap Job Performance karyawan.. 


\section{Author's declaration}

\section{Authors' contributions and responsibilities}

$\checkmark$ The authors made substantial contributions to the conception and design of the study.

$\checkmark$ The authors took responsibility for data analysis, interpretation and discussion of results.

$\sqrt{ }$ The authors read and approved the final manuscript.

\section{Availability of data and materials}

$\sqrt{ }$ All data are available from the authors.

\section{Competing interests}

$\sqrt{ }$ The authors declare no competing interest. 


\section{References}

1) Agarwal, U. A., Datta, S., Blake-Beard, S., \& Bhargava, S. (2012). Linking LMX, innovative work behaviour and turnover intentions: The mediating role of work engagement. Career Development International, 17(3), 208-230. Retrieved from https://doi.org/10.1108/13620431211241063

2) Akgunduz, Y. (2015). The influence of self-esteem and role stress on job performance in hotel businesses. International Journal of Contemporary Hospitality Management, 27(6), 1082-1099. Retrieved from https://doi.org/10.1108/IJCHM-09-2013-0421

3) Altman, Y. (2003). Journal of Managerial Psychology: Editorial. Journal of Managerial Psychology (Vol. 18).

4) Aryee, S., \& Zhen Xiong Chen. (2006). Leader-member exchange in a Chinese context: Antecedents, the mediating role of psychological empowerment and outcomes. Journal of Business Research, 59(7), 793-801. Retrieved from https://doi.org/10.1016/j.jbusres.2005.03.003

5) Babič, Š. (2014). Ethical Leadership and Leader Member Exchange (LMX) Theory. CRIS - Bulletin of the Centre for Research and Interdisciplinary Study, 2014(1), 61-71. Retrieved from https://doi.org/10.2478/cris-2014-0004

6) Bakker, A. B., Schaufeli, W. B., Leiter, M. P., \& Taris, T. W. (2008). Work engagement: An emerging concept in occupational health psychology. Work and Stress, 22(3), 187200. Retrieved from https://doi.org/10.1080/02678370802393649

7) BARRICK, M. R., \& MOUNT, M. K. (1991). the Big Five Personality Dimensions and Job Performance: a Meta-Analysis. Personnel Psychology, 44(1), 1-26. Retrieved from https://doi.org/10.1111/j.1744-6570.1991.tb00688.x

8) Chen, T. Y., Tse, T. H., \& Yu, Y. T. (2001). Proportional sampling strategy: A compendium and some insights. Journal of Systems and Software, 58(1), 65-81. Retrieved from https://doi.org/10.1016/S0164-1212(01)00028-0

9) De Jong, J., \& Den Hartog, D. (2010). Measuring innovative work behaviour. Creativity and Innovation Management, 19(1), 23-36. Retrieved from https://doi.org/10.1111/j.1467-8691.2010.00547.x

10) Dhar, S. G. R. (2017). Article information: Employee Service Innovative Behavior : The Roles of Leader-Member Exchange ( LMX ), Work. International Journal of Manpower, Vol. 38(2), 1-42. Retrieved from https://doi.org/http://dx.doi.org/10.1108/IJM-04-2015-0060 
11) Duncan, P., \& Herrera, R. (2014). The Relationship Between Diversity and the Multidimensional Measure of Leader-Member Exchange (LMX-MDM). Journal of Management Policy and Practice, 15(1), 11.

12) Gottman, J. M., Coan, J., Carrere, S., Swanson, C., Gottman, J. M., Coan, J., ... Swanson, C. (1998). Predicting Marital Happiness and Stability from Newlywed Interactions Published by : National Council on Family Relations Predicting Marital Happiness and Stability from Newlywed Interactions. Journal of Marriage and Family, 60(1), 5-22. Retrieved from https://doi.org/10.1002/job

13) Griffin, M. A., Neal, A., \& Parker, S. K. (2007). A new model of work role performance: Positive behavior in uncertain and interdependent contexts. Academy of Management Journal, 50(2), 327-347. Retrieved from https://doi.org/10.5465/AMJ.2007.24634438

14) Gutermann, D., Lehmann-Willenbrock, N., Boer, D., Born, M., \& Voelpel, S. C. (2017). How Leaders Affect Followers' Work Engagement and Performance: Integrating Leader-Member Exchange and Crossover Theory. British Journal of Management, 28(2), 299-314. Retrieved from https://doi.org/10.1111/1467-8551.12214

15) Hackett, R. D., Farh, J. L., Song, L. J., \& Lapierre, L. M. (2003). LMX and organizational citizenship behavior: Examining the links within and across Western and Chinese samples. Dealing with diversity. Retrieved from https://www.researchgate.net/publication/284492251

16) Joo, B. K. (2012). Leader-Member Exchange Quality and In-Role Job Performance: The Moderating Role of Learning Organization Culture. Journal of Leadership and Organizational Studies. Retrieved from https://doi.org/10.1177/1548051811422233

17) Joseph, D. L., Newman, D. A., \& Sin, H. P. (2011). Leader-Member Exchange (LMX) measurement: Evidence for consensus, construct breadth, and discriminant validity. Research Methodology in Strategy and Management (Vol. 6). Emerald. Retrieved from https://doi.org/10.1108/S1479-8387(2011)0000006012

18) Kim, M. S., \& Koo, D. W. (2017). Linking LMX, engagement, innovative behavior, and job performance in hotel employees. International Journal of Contemporary Hospitality Management, 29(12), 3044-3062. Retrieved from https://doi.org/10.1108/IJCHM-06-2016-0319

19) Kock, N. (2017). Which is the best way to measure job performance: Self-perceptions or official supervisor evaluations? International Journal of E-Collaboration, 13(2), 1-9. Retrieved from https://doi.org/10.4018/IJeC.2017040101

20) Laschinger, H. K. S., Purdy, N., \& Almost, J. (2007). The impact of leader-member exchange quality, empowerment, and core self-evaluation on nurse manager's job satisfaction. Journal of Nursing Administration, 37(5), 221-229. Retrieved from 
https://doi.org/10.1097/01.NNA.0000269746.63007.08

21) Li, X., Sanders, K., \& Frenkel, S. (2012). How leader-member exchange, work engagement and HRM consistency explain Chinese luxury hotel employees' job performance. International Journal of Hospitality Management, 31(4), 1059-1066. Retrieved from https://doi.org/10.1016/j.ijhm.2012.01.002

22) Maroofi, F., \& Navidinya, F. (2011). The measurement of job performance and its impact on effectiveness. International Journal of Business Performance Management, 12(3), 217-227. Retrieved from https://doi.org/10.1504/IJBPM.2011.039887

23) Martin, R., Guillaume, Y., Thomas, G., Lee, A., \& Epitropaki, O. (2016). Leader Member Exchange (LMX) and performance. Hurihu, 69(5), 67-121. Retrieved from https://doi.org/10.1111/peps.12100.This

24) Maslyn, J. M., \& Uhl-Bien, M. (2001). Leader-member exchange and its dimensions: Effects of self-effort and other's effort on relationship quality. Journal of Applied Psychology, 86(4), 697-708. Retrieved from https://doi.org/10.1037/00219010.86.4.697

25) Matta, F. K., Scott, B. A., Koopman, J., \& Conlon, D. (2015). Does Seeing “ Eye To Eye " Affect Work Engagement and Does Seeing "Eye To Eye " Affect Work Engagement And OCB? A Role Theory Perspective on LMX Agreement Department of Management Eli Broad College of Business Michigan State University Department of Man. Academy of Management Journal, 58(6), 1686-1708.

26) Na-Nan, K., Chaiprasit, K., \& Pukkeeree, P. (2018). Factor analysis-validated comprehensive employee job performance scale. International Journal of Quality and Reliability Management, 35(10), 2436-2449. Retrieved from https://doi.org/10.1108/IJQRM-06-2017-0117

27) Park, S., Sturman, M. C., Vanderpool, C., \& Chan, E. (2015). Only time will tell: The changing relationships between LMX, job performance, and justice. Journal of Applied Psychology, 100(3), 660-680. Retrieved from https://doi.org/10.1037/a0038907

28) Pnevmatikoudi, K., \& Stavrinoudis, T. (2016). Classification of hotel performance measurement indicators presented in international scientific research. European Journal of Tourism Research, 12(January 2017), 82-98.

29) Salkind, Nail J. (2010). Proportional Sampling. Sage Publishing. Retreived dx.doi.org/10.4135/9781412961288.n34

30) Schaufeli, W. B., Bakker, A. B., \& Salanova, M. (2006). The measurement of work engagement with a short questionnaire: A cross-national study. Educational and Psychological Measurement, 66(4), 701-716. Retrieved from 
https://doi.org/10.1177/0013164405282471

31) Schermuly, C. C., Meyer, B., \& Dämmer, L. (2013). Leader-member exchange and innovative behavior: The mediating role of psychological empowerment. Journal of Personnel Psychology, 12(3), 132-142. Retrieved from https://doi.org/10.1027/18665888/a000093

32) SETYANI, \& DELLA. (2013). Pengaruh Job Involvement Terhadap Job Performance Dan Organizational Citizenship Behavior Pada Karyawan Pt. Wahana Lentera Raya Gresik. Jurnal Ilmiah Mahasiswa Manajemen, 1(3). Retrieved from http://jurnal.wima.ac.id/index.php/JUMMA/article/view/212

33) Sturman, M. C., Cheramie, R. A., \& Cashen, L. H. (2005). The impact of job complexity and performance measurement on the temporal consistency, stability, and test-retest reliability of employee job performance ratings. Journal of Applied Psychology, 90(2), 269-283. Retrieved from https://doi.org/10.1037/00219010.90.2.269

34) Yulianti, Praptini. 2016. Procedural Justice, Organizational Trust, Organizational Identification dan Pengaruhnya pada Employee Engagement. Jurnal Manajemen Teori dan Terapan, 9(3), 218-233. 